\title{
Genetic Associations Between Clinical Mastitis and Somatic Cell Score in Early First-Lactation Cows
}

\author{
B. Heringstad, ${ }^{*} \dagger^{1}$ D. Gianola, ${ }^{\star} \ddagger$ Y. M. Chang, $\neq$ J. Ødegård, ${ }^{*}$ and G. Klemetsdal ${ }^{\star}$ \\ *Department of Animal and Aquacultural Sciences, Norwegian University of Life Sciences, PO Box 5003, N-1432 Ås, Norway \\ †GENO Breeding and A. I. Association, PO Box 5003, N-1432 Ås, Norway \\ ‡Department of Dairy Science, University of Wisconsin, Madison 53706
}

\section{ABSTRACT}

The objectives of this study were to examine genetic associations between clinical mastitis and somatic cell score (SCS) in early first-lactation cows, to estimate genetic correlations between SCS of cows with and without clinical mastitis, and to compare genetic evaluations of sires based on SCS or clinical mastitis. Clinical mastitis records from $15 \mathrm{~d}$ before to $30 \mathrm{~d}$ after calving and first test-day SCS records (from 6 to $30 \mathrm{~d}$ after calving) from 499,878 first-lactation daughters of 2,043 sires were analyzed. Results from a bivariate linear sire model analysis of SCS in cows with and without clinical mastitis suggest that SCS is a heterogeneous trait. Heritability of SCS was 0.03 for mastitic cows and 0.08 for healthy cows, and the genetic correlation between the 2 traits was 0.78 . The difference in rank between sire evaluations based on SCS of cows with and without clinical mastitis varied from -994 to 1,125 , with mean 0 . A bivariate analysis with a threshold-liability model for clinical mastitis and a linear Gaussian model for SCS indicated that heritability of liability to clinical mastitis is at least as large as that of SCS in early lactation. The mean (standard deviation) of the posterior distribution of heritability was $0.085(0.006)$ for liability to clinical mastitis and $0.070(0.003)$ for SCS. The posterior mean (standard deviation) of the genetic correlation between liability to clinical mastitis and SCS was 0.62 (0.03). A comparison of sire evaluations showed that genetic evaluation based on SCS was not able to identify the best sires for liability to clinical mastitis. The association between sire posterior means for liability to clinical mastitis and sire predicted transmitting ability for SCS was far from perfect.

Key words: clinical mastitis, dairy cattle, genetic correlation, somatic cell score

\section{INTRODUCTION}

Mastitis is an inflammation of the mammary gland associated with elevated SCC. Because high SCC in

Received May 2, 2005.

Accepted January 6, 2006

${ }^{1}$ Corresponding author: bjorg.heringstad@umb.no milk is a response to presence of microbes in the mammary gland, SCC can be used both as an indicator of mastitis and as a measure of response to infection. Thus, it is reasonable to expect that SCC observations taken on healthy and mastitic cows display different distributions, with distinct means and variances. Arguably, SCC records may represent a mixture of at least 2 overlapping distributions. If SCC is a heterogeneous trait, an important question is whether this should be ignored or taken into account in genetic evaluation.

One way to evaluate whether SCC is the same trait in healthy and diseased cows is to use samples from populations with mastitis records. Here, cows could be categorized into "healthy" or "mastitic" classes, for example, and SCC assigned to the appropriate groups could be treated statistically as different traits. The genetic correlation between SCC of cows with and without mastitis can be used as a gauge of the extent to which it can be considered the same trait in the 2 groups.

In many countries, SCS (treated homogeneously) is used as an indirect selection criterion for improving mastitis resistance (Interbull, 2005). However, the nature and the strength of the genetic relationship between SCS and mastitis are far from being clear. For example, it is unknown whether selection for low SCS in healthy cows produces a correlated response in diseased animals, because this has not been tested experimentally. Likewise, it is important to assess the degree of agreement between genetic evaluations of sires based on SCS and evaluations based on clinical mastitis (CM) measured directly. To obtain a reasonably clear picture on these issues, large data sets from populations in which CM is recorded routinely and reliably, such as Norway, are needed.

Heringstad et al. (2000) found an average estimated genetic correlation between $\mathrm{CM}$ and SCC of 0.6 based on literature values. Most estimates of the genetic correlation between $\mathrm{CM}$ and SCC are based on lactation averages (e.g., Carlén et al., 2004; Ødegård et al., 2004). However, neither CM nor SCC is necessarily the same trait throughout lactation. Heringstad et al. (2004) estimated genetic correlations ranging from 0.37 to 0.73 
between CM in different intervals of first lactation. Therefore, we chose to study the associations between CM and SCC within a relatively short time interval. Restricting the study to early first-lactation reduces the chance that the SCC record could be affected by a previous episode of mastitis.

The objectives of this study were 1) to examine genetic associations between CM and SCS in early first-lactation cows; 2) to estimate genetic correlations between first test-day SCS of cows with and without CM, and 3) to compare genetic evaluations of sires based on SCS or CM. Records from first-lactation Norwegian Red (NRF) cattle were used for this purpose.

\section{MATERIALS AND METHODS}

\section{Data}

The data set consisted of SCC and CM records from first-lactation NRF cows. A file was constructed by matching test-day SCC data (Ødegård et al., 2003a) with CM records (Heringstad et al., 2003). Cows in the CM data set that had SCC test-day observations in the interval from 6 to $30 \mathrm{~d}$ after first calving, when cows are at high risk of contracting mastitis (Heringstad et al., 1999), were included. Only SCC records in the range between 5,000 and 6,400,000 cells/mL were accepted (Ødegård et al., 2003a). First test-day SCS (SCS30) was calculated as $\log _{\mathrm{e}}(\mathrm{SCC} / 1,000)$, where $\mathrm{SCC}$ was the first test-day SCC record in the period from d 6 to 30 . A binary variable (CM30) was defined as 1 if the cow had at least one case of veterinary treated $\mathrm{CM}$ in the interval from $15 \mathrm{~d}$ before to $30 \mathrm{~d}$ after first calving, and 0 otherwise. The CM30 information was also used to group cows into 2 classes (mastitis and no mastitis), and 2 "new" traits were created for investigative purposes: first test-day SCS in cows with (SCSCM1) and without (SCSCM0) mastitis. Restriction of the data to the first $30 \mathrm{~d}$ of first lactation reduces the chance that either SCSCM1 or SCSCM0 could be affected by a previous episode of mastitis. The classification was based on mastitis episodes both before and after the test-day SCS measure. This is because SCS may start increasing before clinical signs of mastitis can be observed, and before a cow is treated. A shorter risk period could have been used to make sure that the SCS measure and the CM occurred within a short time interval. However, this would have reduced the data set further, and would have increased the chance that mastitic cows would not have any test-day SCS record within the interval. Alternatively, we could have categorized cows based on presence or absence of mastitis treatment during an interval of, for example, $\pm 15 \mathrm{~d}$ from the cow's first SCS test day. However, this definition would increase the risk that the SCS measure may be affected by a previous
CM episode. Based on these considerations, using the first $30 \mathrm{~d}$ of first lactation was chosen.

All cows had information on CM30 and either SCSCM1 or SCSCM0. The final data set had 499,878 cows, of which $11.1 \%$ had CM during the risk period ( $15 \mathrm{~d}$ before to $30 \mathrm{~d}$ after calving). Summary statistics of the data are given in Table 1. As expected, mean SCS (and its variance) was lower for cows that did not have CM during the period of risk. Cows were daughters of 2,043 sires, they had their first calving between September 1978 and January 1996, and were distributed over 231,769 herd-year classes.

The frequency of CM30 in our data set was $11.1 \%$ (Table 1). This is slightly lower than the mastitis frequency in the total mastitis data set (1.6 million cows), in which the frequency of mastitis in the period from $15 \mathrm{~d}$ before to $30 \mathrm{~d}$ after calving was $11.75 \%$. Because mastitis frequencies in the full and restricted datasets were very similar, the sample of cows used can be considered as representative of the population.

\section{Statistical Models}

The SCS and CM data were analyzed using the following 4 models: 1) univariate linear sire model for SCS30, 2) bivariate linear model analysis of SCSCM0 and SCSCM1, 3) univariate threshold model for CM30, and 4) bivariate analysis with a threshold model for CM30 and a linear Gaussian model for SCS30. Standard REML-BLUP procedures were used for models 1 and 2; here, (co)variance components were estimated and sire PTA predicted using the DMU package (Madsen and Jensen, 2002). A Bayesian approach using Markov chain Monte Carlo (MCMC) methods in the implementation (Sorensen et al., 1995; Sorensen and Gianola, 2002) were used for models 3 and 4.

Univariate Linear Model. The linear sire model used for analysis of SCS30 was:

$$
\mathbf{y}=\mathbf{X} \boldsymbol{\beta}+\mathbf{Z}_{\mathbf{h}} \mathbf{h}+\mathbf{Z}_{\mathbf{s}} \mathbf{s}+\mathbf{e}
$$

where $\mathbf{y}$ is a vector of SCS30 observations; $\boldsymbol{\beta}$ is a vector of systematic effects, including fixed effects of age at first calving (in 15 classes, where $<20$ mo was the first class, $>32$ mo was the last class, and other classes were single months) and of mo-yr of first calving (in 197 classes); $\mathbf{h}$ is a vector of random effects of herd-yr of calving; $\mathbf{s}$ is a vector of random sire effects; $\mathbf{e}$ is a vector of residual effects, and $\mathbf{X}, \mathbf{Z}_{\mathbf{h}}$, and $\mathbf{Z}_{\mathbf{s}}$ are the corresponding incidence matrices. Sire effects were assumed to follow the usual multivariate normal distribution, with null mean and a (co)variance matrix reflecting genetic relationship due to sires and maternal grand-sires. Herd-year and residual effects were assumed to be nor- 
Table 1. Summary statistics of the data set

\begin{tabular}{lc}
\hline No of observations & 499,878 \\
No of sires with daughters & 2,043 \\
No of herd-yr classes & 231,769 \\
No of herd-5-yr period classes & 66,404 \\
First test-day SCS (SCS30), mean (SD) & $4.31(1.15)$ \\
Mean CM30 frequency, \% & 11.1 \\
First test-day SCS for cows with CM30 = 0 (SCSCM0), mean (SD) & $4.27(1.12)$ \\
First test-day SCS for cows with CM30 = 1 (SCSCM1), mean (SD) & $4.61(1.34)$ \\
Mean SCC/1000 for cows with CM30 = 0 & 160 \\
Mean SCC/1000 for cows with CM30 = 1 & 305
\end{tabular}

\footnotetext{
${ }^{1}$ Percentage of cows with at least one case of clinical mastitis in the period from $15 \mathrm{~d}$ before calving to
} $30 \mathrm{~d}$ after first calving.

mally distributed, with null mean and variances $\sigma_{h}^{2}$ and $\sigma_{e}^{2}$, respectively.

Bivariate Linear Model. First test-day SCS of cows with and without mastitis (SCSCM0 and SCSCM1) were analyzed with a bivariate linear sire model. Effects were as in the univariate model, except that they were trait specific. The residual correlation was set to zero, because the 2 traits were measured on different cows, and residual variances were trait specific. Herdyear of calving effects were assumed to be correlated between the 2 traits. Normal distributions were assumed throughout.

Univariate Threshold Model. A threshold-liability model (Wright, 1934; Gianola, 1982; Gianola and Foulley, 1983) was used for analysis of the binary CM30 data. In a threshold model it is assumed that there exists an underlying continuous variable, liability $(\lambda)$, such that the observed binary variable takes value 1 if $\lambda$ is larger than a fixed threshold, and 0 otherwise. With binary data, the threshold and the residual variance $\left(\sigma_{e}^{2}\right)$ are not identifiable; therefore, these parameters were set to 0 and 1 , respectively.

The following linear sire model was assumed for the underlying liability to CM30:

$$
\lambda=\mathbf{X} \boldsymbol{\beta}+\mathbf{Z}_{\mathbf{h}} \mathbf{h}+\mathbf{Z}_{\mathbf{s}} \mathbf{s}+\mathbf{e},
$$

where $\lambda$ is a vector of unobserved liabilities of CM30; $\boldsymbol{\beta}$ is a vector of systematic effects (described later); $\mathbf{h}$ is a vector of herd-5-yr period of calving effects; $\mathbf{s}$ is a vector of sire transmitting abilities; $\mathbf{e}$ is a vector of normally distributed residual effects with mean 0 and variance 1 ; and $\mathbf{X}, \mathbf{Z}_{\mathbf{h}}$, and $\mathbf{Z}_{\mathbf{s}}$ are the corresponding incidence matrices.

The $\boldsymbol{\beta}$ vector included age at first calving ( 15 classes) and mo-yr of first calving (197 classes) effects, as in the linear model. Further, $\mathbf{h}$ is a vector of herd-5-yr period of calving effects, of order 66,404. Here, the herd-yr of calving effects used in the linear model were grouped into coarser herd-5-yr-periods of calving classes, to alle- viate the well known "extreme category problem" of the threshold model.

Prior Distributions for Univariate Threshold Model. Independent proper uniform priors, U(-99, 99), were assigned to each of the elements of $\beta$. Each of the herd-5-yr period of calving effects was assumed, a priori, to be independent and was assigned a normal prior with null mean and unknown variance $\left(\sigma_{h}^{2}\right)$. A multivariate normal prior distribution was used for the sire effects:

$$
\mathrm{p}\left(\mathbf{s} \mid \mathbf{A}, \sigma_{s}^{2}\right) \sim \mathrm{N}\left(\mathbf{0}, \mathbf{A} \sigma_{s}^{2}\right)
$$

where $\mathbf{A}$ is the additive relationship matrix, and $\sigma_{s}^{2}$ is the unknown sire variance. The unknown variance components, $\sigma_{h}^{2}$ and $\sigma_{s}^{2}$, were assigned independent scale inverse $\chi^{2}$ prior distributions, each with 2 degrees of freedom and scale parameter 0.1 . The sire variance was bounded between 0 and $1 / 3$, so that intraherd-5yr heritability could take values only within the 0 to 1 range.

Bivariate Model with One Threshold and One Gaussian Trait. The same linear sire model was fitted to both liability to CM30 and SCS30. In matrix notation, the model fitted can be written as:

$$
\mathbf{y}=\mathbf{X} \boldsymbol{\beta}+\mathbf{Z}_{\mathbf{h}} \mathbf{h}+\mathbf{Z}_{\mathbf{s}} \mathbf{s}+\mathbf{e}
$$

where $\mathbf{y}$ is now a vector of unobserved liabilities to CM and records of SCS30, and other effects are as described previously for the univariate threshold model. Residuals were now assumed to be correlated (because CM30 and SCS30 were recorded on each cow) and to follow the distribution $\mathbf{e} \sim N\left(\mathbf{0}, \mathbf{R}_{\mathbf{0}} \otimes \mathbf{I}\right)$ where $\mathbf{R}_{\mathbf{0}}=$ $\left[\begin{array}{ll}1 & \sigma_{e 1 e 2} \\ \sigma_{e 1 e 2} & \sigma_{e 2}^{2}\end{array}\right]$ is the residual (co)variance matrix and $\mathbf{I}$ is an identity matrix of order 499,878 (Table 1). The residual variance of the binary trait, CM30, was set equal to 1 , so that the residual correlation is $\sigma_{e_{1} e_{2}} / \sigma_{e_{2}}$. 
Table 2. Estimated variance components and heritabilities from a univariate analysis of first test-day SCS (SCS30), together with (co)variances and corresponding heritabilities and correlations from a bivariate analysis of first test-day SCS for cows with (SCSCM1) and without (SCSCM0) clinical mastitis

\begin{tabular}{llllll}
\hline & Univariate & & \multicolumn{2}{c}{ Bivariate } & \\
& SCS30 & & SCSCM1 & SCSCM0 & Covariance \\
\hline Sire (co)variance & 0.022 & & 0.010 & 0.023 & 0.012 \\
Herd-year (co)variance & 0.093 & & 0.182 & 0.096 & 0.084 \\
Residual (co)variance & 1.199 & & 1.583 & 1.124 & 0 \\
Heritability $^{1}$ & 0.067 & & 0.023 & 0.074 & \\
Heritability, intraherd $^{2}$ & 0.072 & & 0.025 & 0.080 & \\
Genetic correlation $^{3}$ & & & & 0.78 \\
Correlation between herd-year effects $^{3}$ & & & & 0.63 \\
\hline
\end{tabular}

${ }^{1}$ Heritability: $\mathrm{h}^{2}=4 \sigma_{\mathrm{s}}^{2} /\left(\sigma_{\mathrm{s}}^{2}+\sigma_{\mathrm{h}}^{2}+\sigma_{\mathrm{e}}^{2}\right)$.

${ }^{2}$ Heritability, intraherd: $\mathrm{h}^{2}=4 \sigma_{\mathrm{s}}^{2} /\left(\sigma_{\mathrm{s}}^{2}+\sigma_{\mathrm{e}}^{2}\right)$.

${ }^{3}$ Standard errors of genetic and herd-year correlations were 0.06 and 0.05 , respectively.

Prior Distributions for the Bivariate ThresholdGaussian Model. Independent proper uniform priors, $\mathrm{U}(-9999,9999)$, were assigned to each of the elements of $\boldsymbol{\beta}$. The herd-5-yr period effects were assigned the multivariate normal prior distribution:

$$
\mathbf{h} \sim N\left(\mathbf{0}, \mathbf{H}_{\mathbf{0}} \otimes \mathbf{I}\right),
$$

where $\mathbf{H}_{\mathbf{0}}=\left[\begin{array}{ll}\sigma_{h 1}^{2} & \sigma_{h 1 h 2} \\ \sigma_{h 1 h 2} & \sigma_{h 2}^{2}\end{array}\right]$ is the (co)variance matrix between herd-5-yr period effects and $\mathbf{I}$ is an identity matrix of order 66,404 (Table 1). The following multivariate normal prior distribution was assumed for the sire transmitting abilities:

$$
\mathbf{s} \sim N\left(\mathbf{0}, \mathbf{G}_{\mathbf{0}} \otimes \mathbf{A}\right),
$$

where $\mathbf{G}_{\mathbf{0}}=\left[\begin{array}{ll}\sigma_{s 1}^{2} & \sigma_{s 1 s 2} \\ \sigma_{s 1 s 2} & \sigma_{s 2}^{2}\end{array}\right]$ is the (co)variance matrix between sire transmitting abilities, and $\mathbf{A}$ is as before. Independent inverse Wishart prior distributions were used for the matrices $\mathbf{H}_{\mathbf{0}}$ and $\mathbf{G}_{\mathbf{0}}$ :

$$
\begin{gathered}
\mathbf{H}_{\mathbf{0}} \sim I W\left(\nu_{h}, \mathbf{V}_{h}\right) \text { and } \\
\mathbf{G}_{\mathbf{0}} \sim I W\left(\nu_{g}, \mathbf{V}_{g}\right),
\end{gathered}
$$

where $\nu_{\mathrm{h}}$ and $\nu_{\mathrm{g}}$ are the degrees of freedom parameters, and $\mathbf{V}_{\mathrm{h}}$ and $\mathbf{V}_{\mathrm{g}}$ are scale matrices. Hyper-parameters were as in Heringstad et al. (2005). A scale inverse $\chi^{2}$ prior distribution with 2 degrees of freedom and scale parameter equal to 4 was assigned to the residual variance of SCS30 $\left(\sigma_{e 2}^{2}\right)$. A bounded uniform prior was used for the residual covariance between CM30 and SCS30 $\left(\sigma_{e 2}\right):\left(\sigma_{e 1 e 2} \mid \sigma_{e 2}^{2} \sim U\left(-\sigma_{e 2}, \sigma_{e 2}\right)\right.$.

Sampling and Convergence Diagnostics. For models 3 and 4, a Gibbs sampler, as in Heringstad et al. (2005), was used to draw samples from marginal posterior distributions of interest. Based on the convergence diagnostics method of Raftery and Lewis (1992) and visual inspection of trace plots, a total chain length of 90,000 iterations of Gibbs were run, after a "burn in" of 10,000 rounds. All 90,000 samples were kept for posterior analyses. The efficient sample size for the parameters varied from 8,541 (HY correlation) to 16,763 (residual correlation). The efficient sample size for sire variance was 10,226 and 16,983 for CM30 and SCS30, respectively.

\section{RESULTS AND DISCUSSION}

\section{Univariate Analysis of SCS30}

Variance components and heritability estimates for SCS30 are given in Table 2. Intraherd heritability of first test-day SCS was 0.07, which is lower than heritability of lactation mean SCS (LSCS), as one would expect, because the latter involves an average. Recent Norwegian studies estimated heritability of 0.11 for LSCS (Ødegård, et al., 2003a, 2004). In a review, Mrode and Swanson (1996) reported an average heritability of 0.11 for LSCS.

\section{Bivariate Analysis of SCSCM1 and SCSCMO}

Estimated (co)variance components of SCS in cows with and without veterinary treated CM are given in Table 2. Intraherd heritability of SCSCM1 and SCSCM0 was 0.03 and 0.08 , respectively, and the estimated genetic correlation between the 2 traits was 0.78 . The heritability of SCSCM0 (0.08) was similar to the estimate from the univariate analysis of SCS30 (Table 2 ), whereas the heritability for SCSCM1 was much lower (0.03). The genetic correlation of 0.78 suggests that SCS is not the same trait in cows with and without 
Table 3. Correlations (above diagonal) and rank correlations (below diagonal) between sire PTAs for SCS and for clinical mastitis from $15 \mathrm{~d}$ before to $30 \mathrm{~d}$ after calving (CM30) from univariate analysis of first testday SCS (SCS30), bivariate analysis of first test-day SCS for cows with (SCSCM1) and without (SCSCM0) clinical mastitis, bivariate analysis with a threshold model for CM30 (CM30-bi), and a Gaussian model for SCS30 (SCS30-bi), and univariate threshold model analysis of CM30 (CM30)

\begin{tabular}{lllllll}
\hline & SCS30 & SCSCM1 & SCSCM0 & SCS30-bi & CM30-bi & CM30 \\
\hline SCS30 & & 0.95 & 0.99 & 0.99 & 0.69 & 0.44 \\
SCSCM1 & 0.96 & & 0.94 & 0.94 & 0.61 & 0.38 \\
SCSCM0 & 0.99 & 0.94 & & 0.97 & 0.64 & 0.38 \\
SCS30-bi & 0.99 & 0.93 & 0.97 & & 0.76 & 0.53 \\
CM30-bi & 0.67 & 0.59 & 0.62 & 0.75 & & 0.94 \\
CM30 & 0.41 & 0.34 & 0.36 & 0.51 & 0.93 & \\
\hline
\end{tabular}

CM. Hence, SCS is clearly a heterogeneous trait, genetically.

The rank correlation between sire PTA for SCSCM1 and SCSCM0 was 0.94 (Table 3). Table 4 shows how the top 10 sires for SCSCM1 ranked for SCSCM0. Although the rank correlation between sire evaluations was 0.94 , there were only 4 common sires among the top 10 for the 2 traits. The top-ranked sire based on SCSCM1 was ranked eighth for SCSCM0, whereas the sire ranked 10th for SCSCM1 had rank 141 for SCSCM0. These differences in ranking are consistent with the hypothesis that SCS is a genetically heterogeneous trait.

Assuming that a low SCS is desirable, sires were ranked based on increasing PTAs for SCS. The differences in rank between sire evaluations for SCSCM1 and SCSCM0 (rank $\mathrm{SCSCM}_{1}-$ rank $_{\mathrm{SCSCM}}$ ) varied from -994 to 1,125 , with mean 0 . The distribution of the changes in ranking is given in Figure 1. The distribution had a large mass near 0 , but changes in ranking of 200 positions or more were frequent.

Figure 2 shows that ranking of the sires with the highest and lowest PTA for SCSCM0 (absolute value larger than 0.2 PTA units) were similar in the 2 evaluations, whereas the rank of many of the sires with intermediate values of PTA for SCSCM0 changed dramatically.

Table 4. The top 10 sires for SCSCM1 and their ranking for SCSCM $0^{1}$

\begin{tabular}{lc}
\hline PTA for SCSCM1 & PTA for SCSCM0 \\
\hline 1 & 8 \\
2 & 16 \\
3 & 23 \\
4 & 5 \\
5 & 20 \\
6 & 2 \\
7 & 1 \\
8 & 34 \\
9 & 24 \\
10 & 141 \\
\hline
\end{tabular}

${ }^{1}$ First test-day SCS for cows with (SCSCM1) and without (SCSCM0) clinical mastitis.
Here, cows were categorized based on phenotypic observations on a genetically correlated trait (CM30). This may arguably lead to ascertainment and selection bias. Because heritability of CM is low and the genetic correlation between CM and SCS is moderately high, selection bias is not expected to be a major problem. The ascertainment bias stems from the fact that disease diagnostic is not perfect (e.g., existence of false negatives). It is unclear how ascertainment bias can affect inferences about the joint distribution of SCSCM0 and SCSCM1.

The results of the bivariate analysis of SCSCM0 and SCSCM1 suggest that SCS is not the same trait in cows with and without CM. Models and procedures that take into account that SCS is a heterogeneous character should therefore be considered for genetic evaluation. Finite mixture models (Ødegård et al., 2003b; Gianola et al., 2004; Gianola, 2005; Ødegård et al., 2005) are appealing candidates for this purpose.

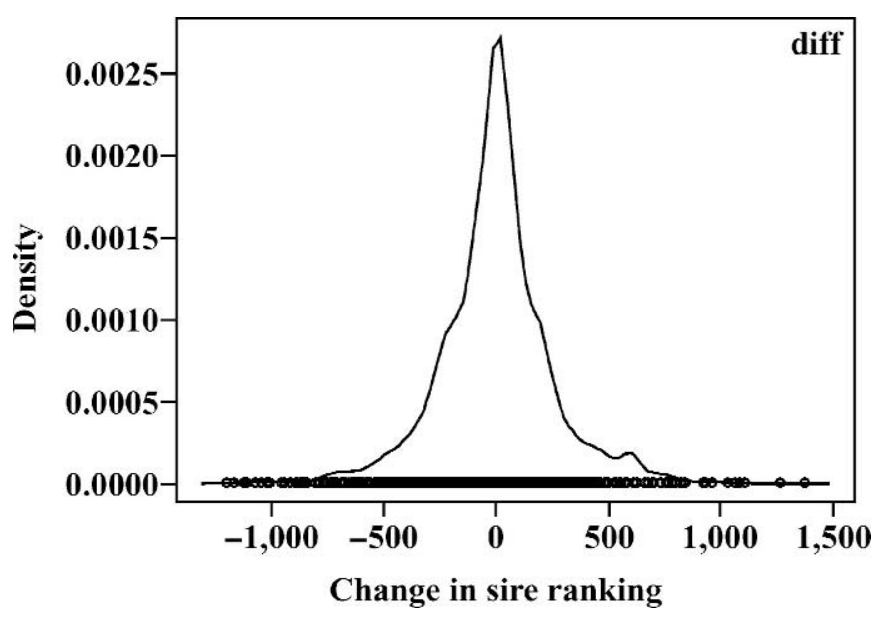

Figure 1. Distribution of the change in sire ranking between evaluations based on first test-day SCS for cows with (SCSCM1) and without (SCSCM0) clinical mastitis $($ Change $=$ rank based on PTA $_{\mathrm{SCSCM} 1}$ - rank based on PTA $\left.\mathrm{SCSCM}_{0}\right)$. 


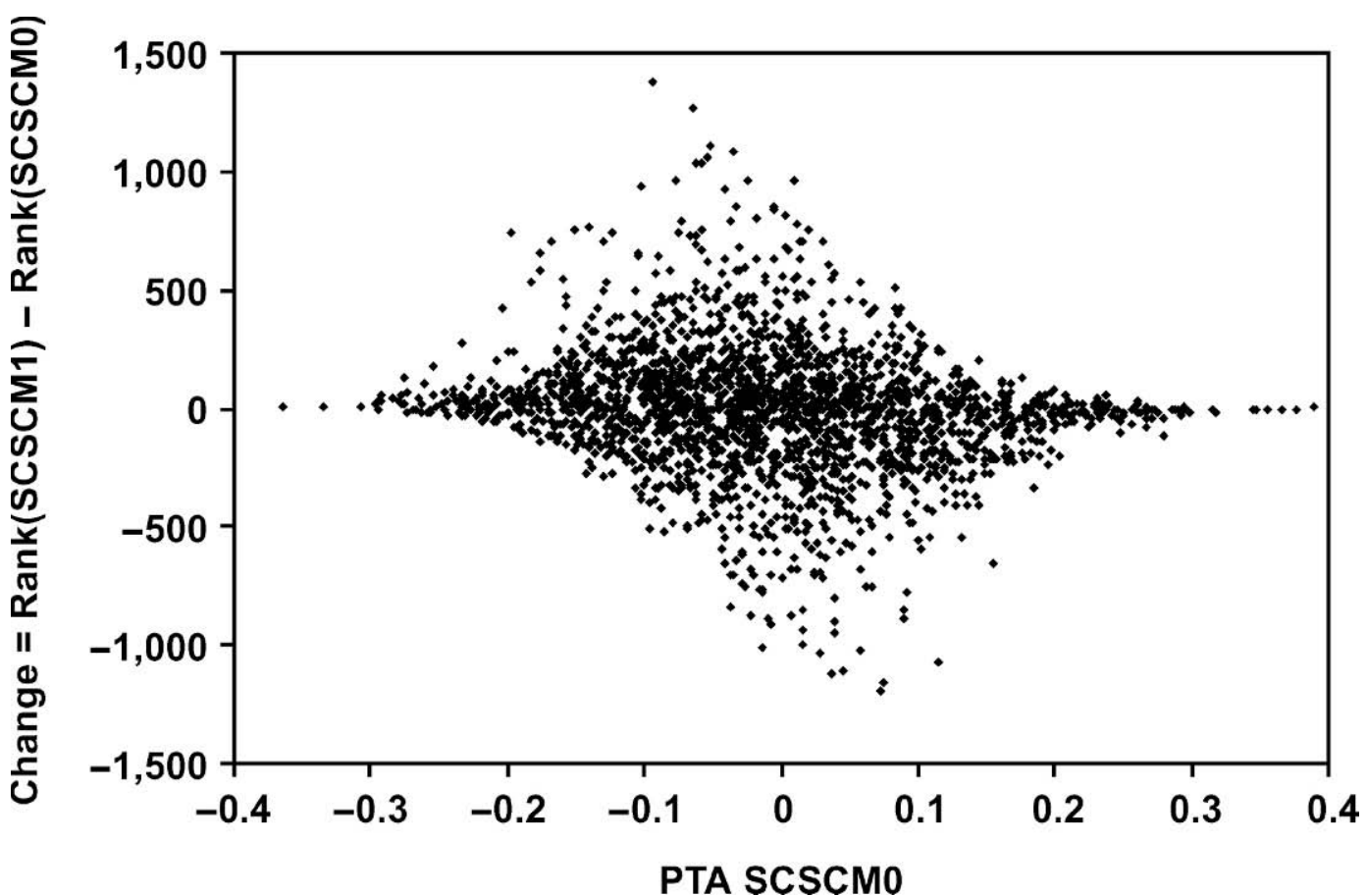

Figure 2. Relationship between change in sire ranking between evaluations based on first test-day SCS for cows with (SCSCM1) and without (SCSCM0) clinical mastitis (rank SCSCM1 - rank SCSCM0) by PTA for SCSCM0.

\section{Bivariate Analysis of SCS30 and CM30}

Posterior means and SD of (co)variance components, correlations, and heritabilities of SCS30 and CM30 are given in Table 5 . The mean (SD) of the posterior distribution of intraherd heritability of SCS30 and of liability to CM30 was $0.070(0.003)$ and $0.085(0.006)$, respec- tively. It appears that, in this population, the heritability of liability to $\mathrm{CM}$ is at least as large as that of SCS, in early lactation. The posterior mean (SD) of the genetic correlation between the two traits was 0.62 (0.03), whereas the posterior means of the residual correlation and of the correlation between herd-5-yr period effects were 0.17 and -0.07 , respectively. The slightly

Table 5. Means and standard deviations (SD) of the posterior distributions of sire, herd-5-yr period, and residual (co)variances, and of corresponding heritabilities and correlations from a bivariate analysis with a threshold model for CM30 and a Gaussian model for SCS30, and from a univariate threshold model analysis of $\mathrm{CM} 30^{1}$

\begin{tabular}{|c|c|c|c|c|c|c|c|c|}
\hline & \multicolumn{6}{|c|}{ Bivariate } & \multicolumn{2}{|c|}{$\begin{array}{l}\text { Univariate } \\
\text { CM30 }\end{array}$} \\
\hline & \multicolumn{2}{|c|}{ CM30 } & \multicolumn{2}{|c|}{ SCS30 } & \multicolumn{2}{|c|}{ CM30-SCS30 } & \multirow[b]{2}{*}{ Mean } & \multirow[b]{2}{*}{ SD } \\
\hline & Mean & $\mathrm{SD}$ & Mean & $\mathrm{SD}$ & Mean & $\mathrm{SD}$ & & \\
\hline Sire (co)variance & 0.022 & 0.001 & 0.022 & 0.001 & 0.014 & 0.001 & 0.022 & 0.002 \\
\hline Herd-5-yr (co)variance & 0.151 & 0.003 & 0.052 & 0.001 & -0.007 & 0.001 & 0.150 & 0.003 \\
\hline Residual (co)variance & 1 & 0 & 1.24 & 0.003 & 0.179 & 0.003 & 1 & 0 \\
\hline Heritability $^{2}$ & 0.074 & 0.005 & 0.067 & 0.003 & & & 0.076 & 0.005 \\
\hline Heritability, intraherd ${ }^{3}$ & 0.085 & 0.006 & 0.070 & 0.003 & & & 0.087 & 0.006 \\
\hline Genetic correlation & & & & & 0.62 & 0.030 & & \\
\hline Herd-5-yr correlation & & & & & -0.07 & 0.016 & & \\
\hline Residual correlation & & & & & 0.17 & 0.002 & & \\
\hline
\end{tabular}

${ }^{1} \mathrm{CM} 30$ is a binary variable defined as 1 if the cow had at least one case of veterinarian-treated clinical mastitis from $15 \mathrm{~d}$ before to $30 \mathrm{~d}$ after calving, and 0 otherewise.

${ }^{2}$ Heritability: $\mathrm{h}^{2}=4 \sigma_{\mathrm{s}}^{2} /\left(\sigma_{\mathrm{s}}^{2}+\sigma_{\mathrm{h}}^{2}+\sigma_{\mathrm{e}}^{2}\right)$.

${ }^{3}$ Heritability, intraherd: $\mathrm{h}^{2}=4 \sigma_{\mathrm{s}}^{2} /\left(\sigma_{\mathrm{s}}^{2}+\sigma_{\mathrm{e}}^{2}\right)$. 
a)

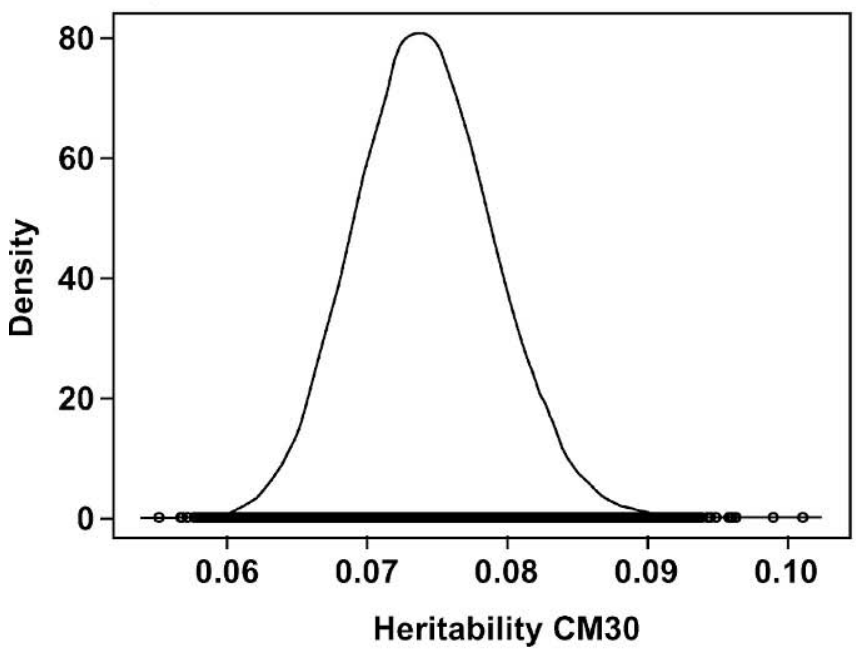

b)

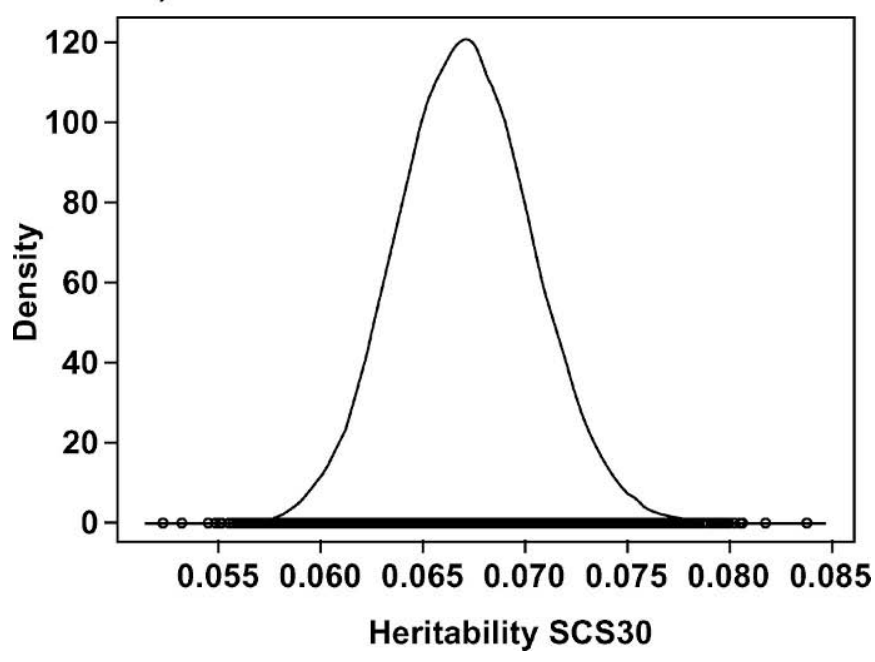

Figure 3. Posterior distributions of intraherd heritability $\left[\mathrm{h}^{2}=\right.$ $\left.4 \sigma_{\mathrm{s}}^{2} /\left(\sigma_{\mathrm{s}}^{2}+\sigma_{\mathrm{e}}^{2}\right)\right]$ of liability to clinical mastitis in the interval from $15 \mathrm{~d}$ before to $30 \mathrm{~d}$ after calving (CM30) and first test-day SCS (SCS30), from a bivariate analysis with a threshold model for CM30 and a Gaussian model for SCS30.

favorable residual correlation suggests a positive association between effects other than herd-5-yr and sire on SCS and CM.

The posterior distributions of heritabilities and of the genetic correlation between the 2 traits were sharp and symmetric, as illustrated in Figures 3 and 4 . A comparison between the posterior distribution of heritability of liability to CM30 and SCS30 reveals that it is unlikely that indirect selection for SCS is more effective than direct selection against CM (using a threshold model) in the NRF population. Further, the posterior distribution of the genetic correlation between the 2 traits indicates that it is very unlikely that this parameter ex-

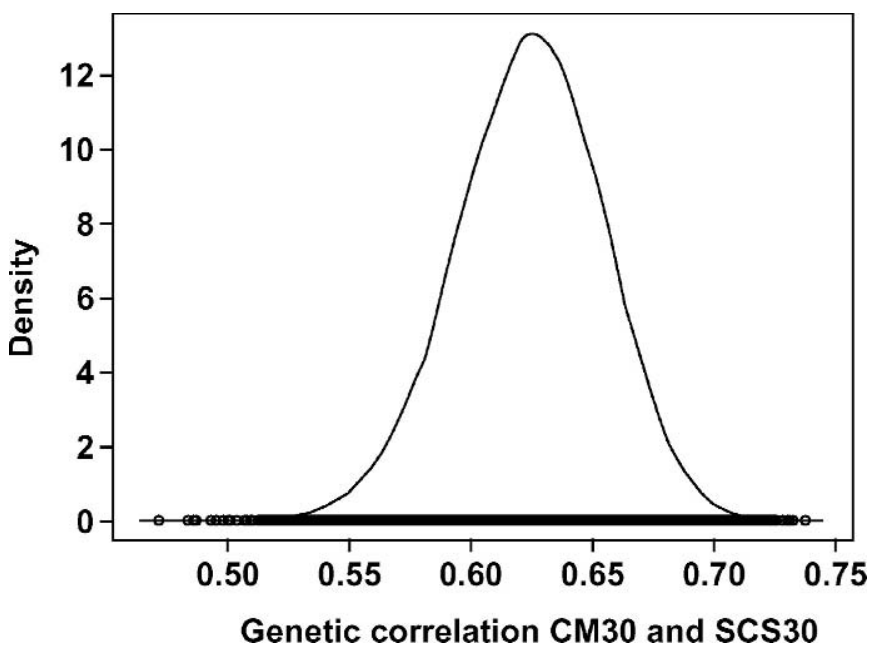

Figure 4. Posterior distribution of the genetic correlation between liability to clinical mastitis in the interval from $15 \mathrm{~d}$ before to $30 \mathrm{~d}$ after calving (CM30) and first test-day SCS (SCS30).

ceeds 0.70 . Taking this upper bound as the true value of the genetic correlation, the implication is that indirect selection based on SCS30 will be less effective than direct selection for decreased liability to CM, at least in early lactation of NRF cows. This is in agreement with Ødegård et al. (2003c), who found that ability to predict CM in future daughters, as a measure of efficiency of selection, was 23 to $43 \%$ higher when based on CM than when LSCS was used for selection.

In a review, Heringstad et al. (2000) found that estimates of the genetic correlation between mastitis and SCC based on Nordic field data varied between 0.3 and 0.8 , with an average of 0.6. Mrode and Swanson (1996) concluded that the average estimated genetic correlation between mastitis and SCC, based on values from the literature, was roughly 0.7 . In a recent Norwegian study (Ødegård et al., 2004), based on 1.4 million cows, the estimate of genetic correlation between $\mathrm{CM}$ and LSCS was 0.53. Koivula et al. (2005) estimated genetic correlations ranging from 0.59 to 0.68 between clinical mastitis and SCC in Finnish Ayrshire. Carlén et al. (2004) estimated genetic correlations between mastitis and LSCS of 0.68, 0.66, and 0.77 for first-, second-, and third-lactation Swedish Holstein. These point estimates, with the exception of the 0.77 of Carlén et al. (2004), enter at reasonably high density in the posterior distribution shown in Figure 4, even though LSCS spans an entire lactation.

\section{Univariate Analysis of CM30}

Variance component and heritability estimates for liability to CM30 were approximately the same in uni- 
Table 6. The top 10 sires for CM30 and their ranking from genetic evaluations of first test-day SCS (SCS30), and first test-day SCS for cows with (SCSCM1) and without (SCSCM0) clinical mastitis

\begin{tabular}{lccc}
\hline CM30 & SCSCM1 & SCSCM0 & SCS30 \\
\hline 1 & 145 & 52 & 43 \\
2 & 132 & 226 & 162 \\
3 & 22 & 26 & 16 \\
4 & 72 & 75 & 47 \\
5 & 166 & 498 & 303 \\
6 & 898 & 1,073 & 872 \\
7 & 68 & 90 & 68 \\
8 & 61 & 86 & 60 \\
9 & 4 & 5 & 3 \\
10 & 942 & 932 & 823 \\
\hline
\end{tabular}

${ }^{1} \mathrm{CM} 30$ is a binary variable defined as 1 if the cow had at least one case of veterinarian-treated clinical mastitis from $15 \mathrm{~d}$ before to 30 $\mathrm{d}$ after calving, and 0 otherwise.

variate and bivariate analyses (Table 5). Correlations between sire posterior means for CM30 from univariate and bivariate analysis were 0.93 (rank) and 0.94 (Pearson) as shown in Table 3.

The posterior mean (SD) of intraherd heritability of liability to CM was 0.09 (0.006; Table 5). This point estimate agrees with other estimates from cross-sectional threshold model analyses of first-lactation mastitis treated as a single binary trait, which range from 0.06 to 0.12 (Lund et al., 1999; Kadarmideen et al., 2001; Heringstad et al., 2003; Zwald et al., 2004).

\section{Genetic Evaluation of Sires Based on SCS vs. CM}

Table 3 shows correlations between sire PTA for SCS and sire posterior means for CM30 from the four models. Rank correlations within trait (SCS or CM) were high (0.93 to 0.99 ), whereas rank correlations between traits were lower ( 0.34 to 0.75 ). These rank correlations imply that different sires would be selected based on whether SCS or CM was used for genetic evaluation.

Table 6 shows the 10 top-ranked sires for CM30 from the univariate analysis and their ranking for the SCSbased selection criteria. Some sires had reasonably good agreement between rankings (e.g., sires ranked as 3 and 9 based on CM30). On the other hand, the sire ranked sixth for CM30 was ranked between 872 and 1,073 when based on the different SCS PTA. Only one sire (9) was among top 10 for all criteria. Hence, selection of sires depends critically on whether genetic evaluation is based directly on CM or on proxy traits like SCS, irrespective of whether this is measured on cows treated for CM or not. Genetic evaluation based on SCS30, SCSCM1, or SCSCM0 was not able to identify the best sires for liability to CM30.

A scatter diagram of sire evaluations based on sire posterior means for liability to CM30 and on sire PTA

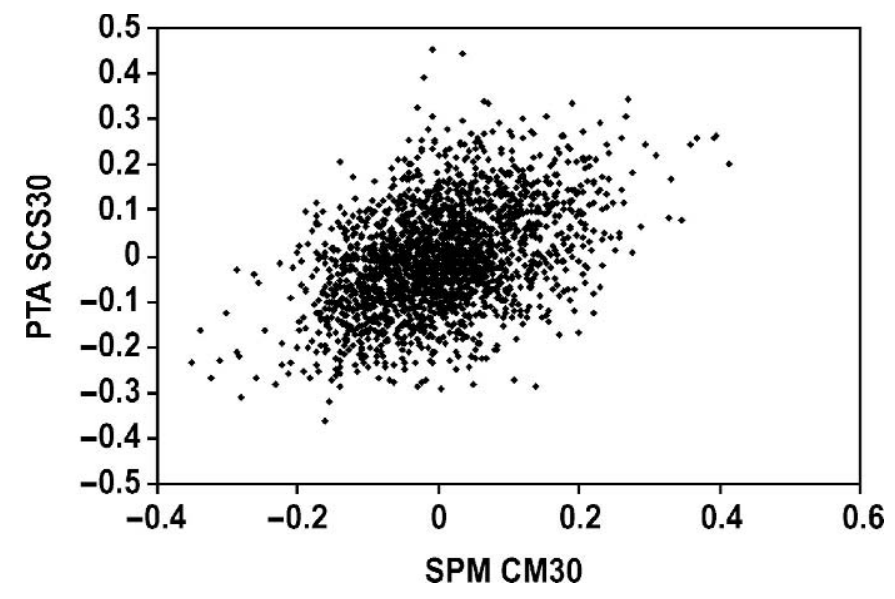

Figure 5. Plot of sire posterior mean (SPM) of liability to clinical mastitis in the interval from $15 \mathrm{~d}$ before to $30 \mathrm{~d}$ after first calving (CM30) against sire PTA for first test-day SCS (SCS30), from univariate analyses.

for SCS30 from univariate analyses is given in Figure 5. The diagram shows clearly that the association between such evaluations is far from perfect. Hence, indirect genetic evaluation based on SCS is not an accurate proxy for genetic evaluation of liability to CM.

\section{CONCLUSIONS}

The genetic correlation of 0.78 between first test-day SCS of cows with and without CM suggests that SCS is not the same trait in the 2 groups of cows. Genetic analysis of SCS might be improved via fitting of mixture models, because these are capable of taking into account the heterogeneity of the trait. Ranking and selection of sires was affected markedly by whether SCS or CM (or both) were used for genetic evaluation.

\section{ACKNOWLEDGMENTS}

Access to the data was given by the Norwegian Dairy Herd Recording System and the Norwegian Cattle Health Service in agreement number 6/1998 and 011.2000. GENO Breeding and A.I. Association is acknowledged for providing pedigree information on sires. This work is part of the "Healthy Cow" project financed by the Research Council of Norway. Support was also received from the Babcock Institute for International Dairy Research and Development, University of Wisconsin, Madison, and by grants NRICGP/USDA 200335205-12833 and NSF DEB-0089742.

\section{REFERENCES}

Carlén, E., E. Strandberg, and A. Roth. 2004. Genetic parameters for clinical mastitis, somatic cell score, and production in the first 
three lactations of Swedish Holstein cows. J. Dairy Sci. 87:3062-3070.

Gianola, D. 1982. Theory and analysis of threshold characters. J. Anim. Sci. 54:1079-1096.

Gianola, D. 2005. Prediction of random effects in finite mixture models with Gaussian components. J. Anim. Breed. Genet. 122:145-160.

Gianola, D., and J. L. Foulley. 1983. Sire evaluation for ordered categorical data with a threshold model. Genet. Sel. Evol. 15:201-224.

Gianola, D., J. Ødegård, B. Heringstad, G. Klemetsdal, D. Sorensen, P. Madsen, J. Jensen, and J. Detilleux. 2004. Mixture model for inferring susceptibility to mastitis in dairy cattle: A procedure for likelihood-based inference. Genet. Sel. Evol. 36:3-27.

Heringstad, B., Y. M. Chang, D. Gianola, and G. Klemetsdal. 2004. Multivariate threshold model analysis of clinical mastitis in multiparous Norwegian Dairy Cattle. J. Dairy Sci. 87:3038-3046.

Heringstad, B., Y. M. Chang, D. Gianola, and G. Klemetsdal. 2005. Genetic associations between susceptibility to clinical mastitis and protein yield in Norwegian Dairy Cattle. J. Dairy Sci. 88:1509-1514.

Heringstad, B., G. Klemetsdal, and J. Ruane. 1999. Clinical mastitis in Norwegian Cattle: Frequency, variance components and genetic correlation with protein yield. J. Dairy Sci. 82:1325-1330.

Heringstad, B., G. Klemetsdal, and J. Ruane. 2000. Selection for mastitis resistance in dairy cattle - A review with focus on the situation in the Nordic countries. Livest. Prod. Sci. 64:95-106.

Heringstad, B., R. Rekaya, D. Gianola, G. Klemetsdal, and K. A. Weigel. 2003. Genetic change for clinical mastitis in Norwegian Cattle: A threshold model analysis. J. Dairy Sci. 86:369-375.

Interbull. 2005. Description of National Genetic Evaluation Systems for dairy cattle traits as applied in different Interbull member countries. Available: http://www-interbull.slu.se/ national ges_info2/framesida-ges.htm Accessed March 30, 2005.

Kadarmideen, H. N., R. Rekaya, and D. Gianola. 2001. Genetic parameters for clinical mastitis in Holstein-Friesians in the United Kingdom: A Bayesian analysis. Anim. Sci. 73:229-240.

Koivula, M., E. A. Mäntysaari, E. Negussie, and T. Serenius. 2005. Genetic and phenotypic relationships among milk yield and somatic cell count before and after clinical mastitis. J. Dairy Sci. 88:827-833.

Lund, M. S., J. Jensen, and P. H. Petersen. 1999. Estimation of genetic and phenotypic parameters for clinical mastitis, somatic cell deviance, and protein yield in dairy cattle using Gibbs sampling. J. Dairy Sci. 82:1045-1051.

Madsen, P., and J. Jensen. 2002. A user's guide to DMU. A package for analysing multivariate mixed models. Version 6 , release 4.3 . Research Centre Foulum, Tjele, Denmark.

Mrode, R. A., and G. J. T. Swanson. 1996. Genetic and statistical properties of somatic cell count and its suitability as an indirect means of reducing the incidence of mastitis in dairy cattle. Anim. Breed. Abstr. 64:847-857.

Ødegård, J., B. Heringstad, and G. Klemetsdal. 2004. Short communication: Bivariate genetic analysis of clinical mastitis and somatic cell count in Norwegian Dairy Cattle. J. Dairy Sci. 87:3515-3517.

Ødegård, J., J. Jensen, P. Madsen, D. Gianola, G. Klemetsdal, and B. Heringstad. 2003b. Detection of mastitis in dairy cattle by use of mixture models for repeated somatic cell scores: A Bayesian approach via Gibbs sampling. J. Dairy Sci. 86:3694-3703.

Ødegård, J., G. Klemetsdal, and B. Heringstad. 2003a. Variance components and genetic trend for somatic cell count in Norwegian Cattle. Livest. Prod. Sci. 79:135-144.

Ødegård, J., G. Klemetsdal, and B. Heringstad. 2003c. Genetic improvement of mastitis resistance: Validation of somatic cell score and clinical mastitis as selection criteria. J. Dairy Sci. 86:4129-4136.

Ødegård, J., P. Madsen, D. Gianola, G. Klemetsdal, J. Jensen, B. Heringstad, and I. R. Korsgaard. 2005. A Bayesian thresholdnormal mixture model for analysis of a continuous mastitis-related trait. J. Dairy Sci. 88:2652-2659.

Raftery, A. L., and S. Lewis. 1992. How many iterations in the Gibbs sampler? Pages 763-774 in Bayesian Statistics 4. J. M Bernando, J. O. Berger, A. P. Dawid, and A. F. M. Smith, ed. Oxford University Press, Oxford, UK.

Sorensen, D., and D. Gianola. 2002. Likelihood, Bayesian, and MCMC methods in quantitative genetics. Springer-Verlag, New York, NY.

Sorensen, D. A., S. Andersen, D. Gianola, and I. Korsgaard. 1995. Bayesian inference in threshold models using Gibbs sampling. Genet. Sel. Evol. 27:229-249.

Zwald, N. R., K. A. Weigel, Y. M. Chang, R. D. Welper, and J. S. Clay. 2004. Genetic selection for health traits using producerrecorded data. I. Incidence rates, heritability estimates, and sire breeding values. J. Dairy Sci. 87:4287-4294.

Wright, S. 1934. An analysis of variability in number of digits in an inbred strain of Guinea pigs. Genetics 19:506-536. 